
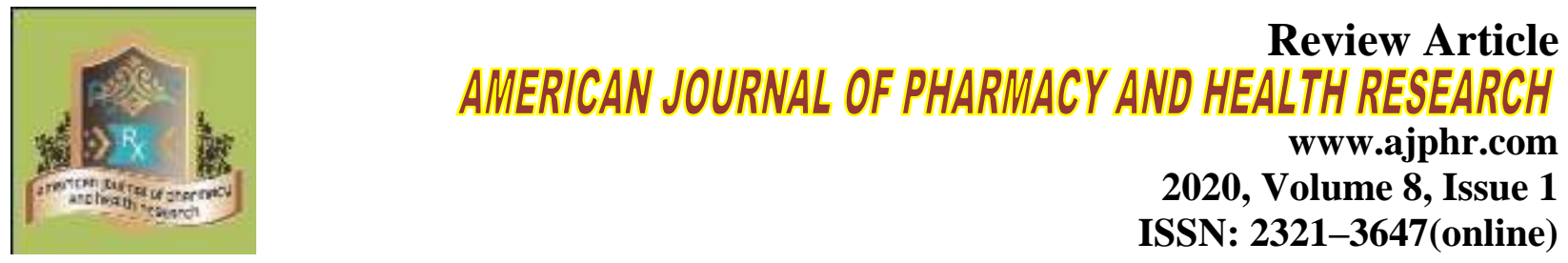

\title{
Mother and Child Wellbeing In Unani System Of Medicine
}

\author{
Aisha Perveen ${ }^{1 *}$, Nasreen Jahan ${ }^{2}$, Md Tanwir Alam, ${ }^{3}$ Shaista Perveen ${ }^{4}$ \\ 1.Regional Research Institute of Unani Medicine(Under CCRUM, Govt. of India, New Delhi), \\ Gujri, Patna City., \\ 2.Dept. of Ilmul Advia, National Institute of Unani Medicine, Kottigepalaya, Magadi Main Road, \\ Bangalore-560091, \\ 3.Dept. of Tahaffuzi Wa Samaji Tib (Community Medicine), Govt. Tibbi College \& Hospital \\ Patna. \\ 4. Dept. of Ilmul Advia, NIUM, Bengaluru.
}

\begin{abstract}
One of the most powerful relationships is in between a mother's health and her child's overall development. Throughout the world, especially in the developing countries, there is an increasing concern and interest in maternal and child health care. Woman is major determinant for her family's development and indirectly to a nation so higher priority should be laid on policies for woman and child health. Unani can help improving Mother and Child Health (MCH) through increased access to low cost high quality healthcare, free from undesirable side-effects. This article emphasizes the Unani ways to conserve and maintain $\mathrm{MCH}$ so as to provide a healthy environment to upcoming generation. It highlights the potentials of Unani medicine and suggests ways to adopt these practices.
\end{abstract}

Keywords: Mother and child health; MCH; Unani Medicine; AYUSH; Maternal. 


\section{INTRODUCTION}

The health of mothers and children is a key indicator of general health of any nation. India's goal is to lower maternal mortality to less than 100 per 100,000 live births but that is still far away despite its programmatic efforts and rapid economic progress over the past two decades. Pregnant women, infants and small children are more susceptible to infections and diseases. They are most dependent and least powerful members of any society, and thus need greater care and attention than other. The health of mothers, infants, children \& adolescents and their profession way within public health committed to promoting the health status and future challenges of this vulnerable population is referred as $\mathrm{MCH} .{ }^{1}$ Six key dimensions of health systems functioning - safety, effectiveness, responsiveness or patient-centered care, timeliness, efficiency and equity - have been identified as critical priorities for quality improvement. India has various maternal health initiatives, with more than two decades of dedicated safe motherhood programming. Yet, an estimated 56,000 maternal deaths take place in the country every year, which is 19 percent of annual maternal deaths taking place globally. ${ }^{2}$ These achievements need to be studied in the light of quality of care, which could provide critical input in planning for institutionalizing quality improvement in services. A country like India has its own cultural and social realities, so it is dire need to chart out solutions which are women and child centered, culturally acceptable, cost effective and easily accessible. Unani medicine is full of wide heritage which are free from side effects and most importantly away from resistance development as happening in case antibiotics to tackle these problems. Therefore, Unani medicine can protect \& preserve health through lifestyle changes i.e. curing of the diseases through food and alteration in daily routine. Approach of Unani system of medicine in area of maternal \& child health that can be implemented in MCH programme is summarized in this article.

\section{Health promotion in non-pregnant/ pregnant woman}

According to Unani system of medicine, care of the woman's health, taken into consideration much earlier than her actual pregnant state. The nutritional status of parents, particularly woman has a direct effect on health of children and upcoming children. USM lays great emphasis on healthy lifestyle through Asbab e sitta zaroriya (six essentials of life). These are set of six essential rules which govern the body functioning to balance and optimum level thereby maintain the health. These rules emphasize the combination of purified and fresh air to breath (Hawa-e-Muheet), proper and timely food and drink (Makool wa Mashroob), right amount of Physical activity and rest (Harkat wa Sukoon-e-Badani), Mental activity and repose (Harkat wa 
Sukoon-e-Nafsani), balanced sleep and wakefulness pattern (Naum wa Yaqza), poper retention and elimination (Ehtibas wa Istifragh).

Women and children are more prone of the air bone diseases caused by seasonal or natural changes and environmental pollution of air. In every season the air changes into another temperament. Change in character of atmospheric air produce changes to human body. Polluted air induces putrefaction to humours. Air performs the function of Ta"adeel-e-Rooh at the time of inspiration by exchanging the air. Simultaneously it also works as Tankiya-e-Rooh at the time of expiration. So fresh and pure air is very necessary to perform physiological functions and to maintain health. We can control and prevent most of the chronic lifestyle diseases through strengthening of rooh \& immunity by breathing in fresh and pure air. ${ }^{3,4}$ Food and drinks is one of the important factor effecting women mothers and children. Unani physicians had advocated precise diet for specific disease, age and need. [6,9] A wholesome diet, based on locally available foods and herbs, compatible to ones' own body constitution, body requirements and seasons is advocated by Hippocrates, Galen and Ibn Sina, the original pioneers of Tibb. ${ }^{4,5,6,7,8}$ In fact, most chronic disorders is either from malnutrition or overeating. Anemia, Diabetes, obesity, heart disease, inflammatory diseases, some skin disorders and cancer can trace their origin back to poor or unwise consumption of food - too much salt or fat; too little fiber; not enough fruit and vegetables; bad eating habits, etc. In USM philosophy, the concept of the qualities of heating and cooling, moistness and dryness, is linked to the effect of different foods have on the person bodily metabolism and formation of the humours. Heating foods will increase the body basic metabolic rate, and cooling foods will have the opposite effect. For some diseases, like phlegmatic disorders, heating foods should be used. For other disorders, like gastritis, cooling foods are more beneficial. Similarly right amount of Physically active and emotional stability is very necessary for women, pregnant women and children for ensuring health and well-being as these help in controlling hormone level, activation of hararat ghariziya (innate energy) and to excrete the waste products. ${ }^{9,10}$ During pregnancy women should be given lateef kaseer ut taghziya ghiza i.e. easy digestible with high nutrition having haar ratab nature as this completes in both mother and fetus nutritional need. In addition to these blood forming medicinal foods should be added in diet such as dates, jaggery, pomegranate and food cooked in iron vessels. USM and Tibbi nabawi advocates the use dietary supplement Talbina (made from Dates and Jau) as it complete the need pertaining to calcium and iron intake. Jwarish Anarain and Jawarish Tamarhind can be given to control digestion related problems and vomiting. Pregnancy constipation problem should be taken care by safe laxatives like mawaiz munaqqa, 
ispagol husk or rogan badam shreen in milk. In last trimester use of ghee and butter is advocated by physicians so as to cover the subcutaneous fat formation need of the fetus and at same time help in smoothening of birth passage. Cough and cold too can be treated easily with decoction made of herbs like ginger, tulsi, podina,laung, unnab, sapistaan. Herbal plants have been used as domestic medicine for child birth for decades and are well recognized from the ancient ages, which are now turned as medicinal plants. ${ }^{11}$ Medicines having emmenagogue/ oxytocics property are usually helpful in inducing and augmenting the labour process, which helps in the expulsion of fetus and placenta e.g., sudaab, sheetraj hindi, chirchita, darchini, taj, juntiana, behroza e khush musaffi, ispand, bekhe kapas, ferfyun and borax are good medicine for easing labor mentioned in classical Unani texts. ${ }^{12,13}$ The nursing mother should take moderate exercise daily and eat wholesome food. During the period of nursing, she should abstain from sexual intercourse as it would activate the menstrual flow and make the milk foul and deficient. ${ }^{14}$ Mother should avoid Onion, Garlic, Rai, Hing and hot spices. Sleep should be encouraged to assist digestion. $6,8,15$

\section{Health promotion in infancy and childhood}

Infancy is the earliest period i.e. from birth to childhood and each day is very important during this part of life. According to USM infancy and childhood are the age of growth and development having Mizaj (temperament)- Har Ratab (hot wet). The legend philosophers of USM, like Ibn Sina (Avicenna), Ibn Hubl Baghdadi, Rabban Tabri and others, have described their views regarding child health in detail and also suggested regimens and drugs for betterment of infants. First consideration should be given to the management of the diseases in lactating mothers for the treatment of infants because a healthy mother assures healthy baby. ${ }^{6,15}$

The umbilical cord care is described as cutting the cord at four finger distance from the umbilicus, then tying it with a soft clean and lightly twined woolen thread then dressing it piece of clean gauze dipped in olive oil. ${ }^{16,17}$ the wound later should be dusted with fine powder made of equal parts of turmeric, Indian kino, Anzaroot, Cumin seeds and Lichen. ${ }^{6,}{ }^{18}$ Clean ear and nose with cotton bud. After delivery the face and skin of the baby should be cleansed as early as possible with saline water and salt, so as to tone up the skin. ${ }^{3,18,19,20}$ Care should be taken to prevent the saline entering into the baby's nose and mouth. The nostrils should be cleansed with the tip of the little finger. 10. In order to dilate the anus the little finger should be used. ${ }^{6,19}$ At this stage the body should be bathed with lukewarm water. 6,19

Eyes should be wiped regularly with a piece of soft linen and head should be covered with properly fitted cap. The bladder should be gently pressed to assist the voidance of urine. ${ }^{18}$ At the 
end of each session arms should be placed by the side of thighs. ${ }^{21}$ In summer season baby should be bathed with tepid water and in winter with moderately warm water. The bath is best given after a prolonged spell of sleep and on empty stomach. ${ }^{3}$ Baby should be fed as far as possible on mother's milk, which is best diet, as it is nearest to the blood from which the baby has grown up as the fetus. $., 15,19$ The breast feeding in the beginning should be given only two or three times a day 11 and avoidance from large feeds especially during the first few days. Light diet and massaging of the neck with olive oil is also beneficial during dentition. Root of the tongue should be regularly massaged to strengthen it as baby begins to talk. ${ }^{6,8}$

There are various diseases which can affect the children such as Diarrhea, flatulence, cold \&cough, conjunctivitis, constipation, earaches etc. Diarrhea is quite common during dentition. Fomentation should be done with paste made of seeds of rose, celery or plaster of cumin seeds and rose seeds made up with vinegar over the abdomen. Milk should be substituted with light foods such as yolk of half boiled egg, soft bread, or flour of roasted barley cooked in water and boiled Cold water should be given. ${ }^{6,22}$ For inflamed gums soothing during Teething piece of asalussus should be given to child. ${ }^{18}$ If convulsions occur during teething it should be treated with light massage oil of iris, lily and henna or roghan banafsha. For conjunctivitis eyelids should be painted over with Barberry mixed with milk, and later on the eyes are washed with a decoction of chamomile and juice of wild basil. ${ }^{6,8}$ In case of excess flatulence, the decoction of anisoon, pudina, sowa, saunf, ajwain is advisable. ${ }^{6,8,22}$ Constipation if occur should be treated with oral honey and suppository made of pure solidified honey or honey mixed with a small quantity of wild mint or plain or burnt lily roots.10 When there is a cough or cold, hot water should be poured freely over the head. ${ }^{3}$ Gum acacia Gum tragacanth, powdered Quince (Cydonia oblonga) seeds and extract of liquorice (Glycyrrhiza glabra) mixed with sugar or Sharbat Khashkhas are given daily in small doses with fresh milk. ${ }^{6,8,22}$ If children develop earache drop made by boiling and filtering of oil in which barberry rock salt, lentil, myrrh, colocynth seeds or juniperis used. For disturbed sleep and insomnia digestion and night mares digestion imbalance should be checked and on head a paste made of poppy seed \& poppy oil or roghan kaddu should be applied..$^{6,8}$

Emotional need of Children should be carefully attended and supervised regarding their behavior keeping them in limits of moderation. A check on their violent behavior, anxiety and anger should kept. ${ }^{15,18}$ Children should be kept away from sadness and fear as these possess negative impact on their development affecting the temperament and produces various types of imbalances like anger produces an unusual degree of heat in the body and sorrow leads to undue 
dryness. ${ }^{6,8,19}$ Infants should be given bath prior to breakfast and allowed to play then given another bath before next feed. ${ }^{3}$ At the age of three years, after awakening in the morning light exercise, massage and then bath are recommended. Children should be allowed to drink as much of the sweet and pure water as they like but avoiding during the meals as it leads to premature absorption of partially digested food. The same regimen, with suitable modification, should be continued up to the age of fourteen. These are few important points described here but vast and elaborated care is described for each and every need of child in classical Unani text.

\section{CONCLUSION}

Improving the health status of mothers and children can be achieved through education, care and prevention. There is a need to adopt those measures which are easily available, cost-effective, free from undesirable effects, socially acceptable and whose cultural implementation is easy compatible to our country standards. USM has a detailed regimen based on various phases and health care needs through foods and herbs. Promoting wellness through continuum of comprehensive healthcare programs can only be achieved by incorporating USM in AYUSH wellness center programs. There utter needs to take measure in right direction.

\section{ACKNOWLEDGEMENT}

Author(s) acknowledge all the writers and authors whose reference has been cited/mentioned in this article.

\section{REFERENCES}

1. https://www.encyclopedia.com/education/encyclopedias-almanacs-transcripts-andmaps/maternal-and-child-health. (cited on 20th July 2019)

2. World Health Organization. Trends in maternal mortality: 1990 to 2010. WHO, UNICEF, UNFPA, and the World Bank Estimates. Geneva: WHO; 2012.

3. Nafees I. Kulliyat-e-Nafeesi, (translation and elaboration) sharah by Hkm Kabiruddin, Vol-1, Idara -e -Kitab us Shifa, New Delhi. 188, 189, 214, 234.

4. Glynn J, Vallee NB et al. Dietotherapy: Let food be your medicine. 2013.

5. Sina I. Al Qanoon fit Tib (English Translation of the critical Arabic text). Book 1. Jamia Hamdard, New Delhi.1993.

6. Sina I. Al Qanoon fil Tibb, Urdu translation by Hkm Ghulam Hasnain Qantoori, Idara e Kitab us Shifa, New Delhi, 2010; 97,109,174, 203-204.

7. Ahmad SI. Introduction to Al Umoor Al Tabiyah, 1st edition, Saini printers, New Delhi.1980 
8. Gruner, OC. A Treatise on the Canon of Medicine of Avicenna, AMS press, New York. 1973; 173: 177.

9. Nafees. Kulliyat e Nafeesi, (translation and elaboration) sharah by Hkm Kabiruddin, Vol1, Idara e Kitab us Shifa, New Delhi. 188, 189,214,234.

10. Zaid H, Said O, Hadieh B et al. Diabetes prevention and treatment with Greco-Arab and Islamic-based natural products., 2011; 15.

11. https://www.c3health.org/blog/review-benefits-physical-activity/ (cited on 10-01-2020)

12. Chakraborty I, Ghosal S et al. Jussiaea repens (L) Acts as an Uterotonic agent - An in vitro study. Int J Pharm Sci Re. Res. 2014; 27: 368-372.

13. Ghani N. Khazainul Advia. Idarae Kitabus Shifa, New Delhi, USA. 2001.

14. Rushd I. Kitabul Kulliyat. CCRUM, New Delhi, second Edition 1987.

15. Tabri R. Firdaus-ul-Hikmat. Idara Kitab-u-Shifa, New Delhi, 2010.

16. Azmi HKAS. Amrazul Atfal. Qaumi Council Barai Faroogh Urdu Zaban, New Delhi, 3rd Edition 2001.

17. Ilahi A. Usoolo Tadabeer Hifzane Sehat. Liberty Art Press, New Delhi, First Edition 2010.

18. Jurjani AH. Zakhira Khawarazm Shahi. Idara Kitab us Shifa, New Delhi, 2010.

19. Baghdadi IH. Kitab Al Mukhtarat fil Tib. CCRUM, New Delhi, Vol 1. 2010: 182-190.

20. Majoosi AA. Kamil ul Sanah (Urdu translation). Idara Kitabus Shifa, New Delhi, 2010

21. Sathy N. Practical Paediatrics. Reed Elsevier, New Delhi, Second Edition 2005.

22. Hafeez I, Alam SS. Moalajat Amraze Atfal. Alok Press, Bhopal, First Edition 2009. 